\title{
RECONHECIMENTO DE SABERES E COMPETÊNCIAS: um olhar histórico sobre a carreira do professor da Educação \\ Profissional
}

\author{
Solange Rodrigues* \\ Maria Auxiliadora Monteiro Oliveira**
}

\section{RESUMO}

Este artigo tem o objetivo de apresentar parte da tese "Reconhecimento de Saberes e Competências (RSC) dos professores do IFMG: uma (re)constituição do discurso histórico-social sobre a implementação da Lei do Magistério Federal" que trata da história da carreira do professor da educação profissional (EBTT), incluindo o dispositivo do Reconhecimento de Saberes e Competências da lei em vigor. Essa lei determina que esse reconhecimento ocorra por meio de aumento salarial aos professores que pleitearem o RSC. Por fim, algumas considerações são apresentadas sobre esse dispositivo no contexto atual da nossa sociedade.

Palavras-chave: Políticas Públicas. Reconhecimento de Saberes e Competências: Carreira do EBTT.

\begin{abstract}
This article aims to present part of the thesis "Recognition of Knowledge and Competences (CSR) of IFMG teachers: a (re) constitution of the historicalsocial discourse on the implementation of the Federal Magisterium Law" that deals with the career history of the IFMG. professional education teacher (EBTT), including the provisions of the Recognition of Knowledge and Skills of the law This law requires this recognition to occur through salary increases for teachers applying for CSR. Finally, some considerations are presented about this device in the current context of our society.
\end{abstract}

Keywords: Public policy. Recognition of Knowledge and Skills: EBTT Career
*Doutoranda em Educação (PUC Minas), Professora do IFMG-Ouro Preto. E-mail: solange.rodrigues@ifmg.edu.br

** Doutora em Educação (UNICAMP) e Pós-Doutora em Educação (UNICAMP E Universidade do Porto), Professora do Programa de Pósgraduação em Educação da PUC Minas. E-mail: dorinhapuc@hotmail.com 
A aspiração à emancipação não se interpreta como a conquista de um direito individual profissional, mas como a construção das conexões entre a realização da prática profissional e o contexto social mais amplo, que também deve transformar-se. (Ghedin, p. 161-163)

\title{
1 HISTÓRICO DA CARREIRA DO PROFESSOR DA EDUCAÇÃO PROFISSIONAL
}

Por muitos anos, a carreira do professor da Educação Profissional foi normatizada pelo Regime Jurídico Único e o servidor docente era categorizado como Professor de $1^{\circ}$ e $2^{\circ}$ graus. Isso ocorreu até 30 de junho de 2008. A partir de $1^{\circ}$ de julho de 2008 até atualidade, o servidor docente enquadrou-se na carreira do Professor do Ensino Básico, Técnico e Tecnológico (EBTT), mudança determinada pela Lei $\mathrm{n}$. 11784 , de 22 de setembro de 2008.

Nas últimas três décadas, tem-se observado algumas alterações na estrutura e organização do Estado, deixando explicitar a implementação de políticas neoliberais em vigor na sociedade. No âmbito educacional, recentemente, há a imposição dos ideais do Projeto Escola sem Partido, a reestruturação do Ensino Médio e da carreira do professor da Educação Profissional.

\begin{abstract}
O predomínio do pensamento neoliberal é evidente nas concepções sobre o trabalho docente presente no desenvolvimento da carreira ou quando as condições de trabalho são diretamente associadas à "meritocracia" - aos aspectos de um beneficiamento individualizado. Tal concepção está impregnada pelo produtivismo que ocorre fundamentado nas regulamentações que estabelecem tabelas de pontuações para cada ação do docente, vinculando-as à conquista de benefícios. Sob essa concepção, a carreira e o trabalho docente reforçam o "individualismo" e a "meritocracia", já que defende que o "sucesso" e o "benefício" são alcançados de acordo com a produtividade de cada pessoa. (SANTOS; CHAVES, 2017, p. 85)
\end{abstract}

A luta por melhoria de condições salariais e de trabalho concretiza-se, majoritariamente, nas reivindicações de aprovação de planos de carreiras referentes a uma determinada categoria profissional. $\mathrm{O}$ objeto deste artigo refere-se ao dispositivo do Reconhecimento de Saberes e Competências, presente na Lei n. 12772/2012 que estrutura o atual Plano de Carreiras e Cargos do Magistério Federal. 
Desde o início do século XX até os dias de hoje, foram implementados três planos de carreiras para os servidores da Educação Profissional. O primeiro, em 1970; o segundo, em 1987 e o terceiro, em 2008.

A Lei n. 12772/12 enquadra-se no terceiro plano. Segundo Dominik (2017), um plano pode abranger diversas carreiras, como ocorre com o atual Plano de Carreiras e Cargos do Magistério Federal. Um plano de cargos e carreiras não precisa, necessariamente, normatizar e regulamentar a atividade de apenas uma categoria profissional. Isso está disposto na Lei do Magistério Federal, que estrutura não apenas a carreira dos docentes, mas também dos demais servidores vinculados às Universidades Federais e às instituições que compõem a RFEPCT1. Trata-se, portanto, de uma legislação que normatiza as carreiras e cargos de servidores vinculados às instituições educacionais, no âmbito federal. Para melhor visualizar essas informações históricas, segue o quadro dos planos de carreiras dos docentes da Educação Profissional Federal.

Quadro 1: Planos e Carreiras dos Professores da Educação Profissional NOMENCLATURA DAS CARREIRAS DA EDUCAÇÃO PROFISSIONAL FEDERAL

\begin{tabular}{|c|c|c|c|}
\hline Ano & Plano de Carreira & Ano & Carreira \\
\hline \multirow{2}{*}{1970} & \multirow{2}{*}{$\begin{array}{c}\text { Plano de Classificação de Cargos } \\
\text { do Serviço Civil da União e das } \\
\text { Autarquias Federais - Grupo } \\
\text { Magistério do Serviço Civil da } \\
\text { União e das Autarquias Federais } \\
\text { (Lei no 5.645/1970) }\end{array}$} & 1974 & $\begin{array}{c}\text { Categoria Funcional do } \\
\text { Professor de Ensino de } 1^{\circ} \text { e } 2^{\circ} \\
\text { graus }\end{array}$ \\
\hline & & 1981 & $\begin{array}{c}\text { Carreira do Magistério de } 1^{\circ} \mathrm{e} \\
2^{\circ} \text { Graus do Serviço Público } \\
\text { Civil, da União e das } \\
\text { Autarquias Federais }\end{array}$ \\
\hline \multirow[b]{2}{*}{1987} & Plano Único de Classificação e & 1987 & \multirow{2}{*}{$\begin{array}{l}\text { Carreira do Magistério de } 1^{\circ} \mathrm{e} \\
\qquad 2^{\circ} \text { Graus }\end{array}$} \\
\hline & $\begin{array}{c}\text { Empregos - PUCRCE (Lei n } \\
7.596 / 1987)\end{array}$ & 2006 & \\
\hline \multirow[b]{2}{*}{2008} & Plano de Carreira e Cargos de & 2008 & \multirow{2}{*}{$\begin{array}{c}\text { Carreira de Magistério do } \\
\text { Ensino Básico, Técnico e } \\
\text { Tecnológico }\end{array}$} \\
\hline & $\begin{array}{l}\text { Magistério do Ensino Básico, } \\
\text { Técnico e Tecnológico (Lei n } \\
11.784 / 2008)\end{array}$ & 2012 & \\
\hline
\end{tabular}

\footnotetext{
${ }^{1}$ A RFEPCT, instituída pela Lei n. 11892/2008, foi constituída pelas seguintes instituições: Institutos Federais de Educação, Ciência e Tecnologia; Universidade Tecnológica Federal do Paraná - UTFPR; Centros Federais de Educação Tecnológica Celso Suckow da Fonseca - CEFET-RJ e de Minas Gerais CEFET-MG; Escolas Técnicas Vinculadas às Universidades Federais; e o Colégio Pedro II.
} 
Fonte: Dominik (2017, p.16)

Como se pode observar, as nomenclaturas das carreiras mantêm relação com a legislação educacional que vigora em cada época. Os termos $1^{\circ}$ e $2^{\circ}$ graus coadunam com a nomenclatura dos níveis de ensino utilizada pela Lei n. 5692/71 e os termos Ensino, Básico, Técnico e Tecnológico relacionam-se com a implementação dos Institutos Federais de Educação Profissional, pela Lei n. 11.784/2008, conforme se observa no quadro 2.

\begin{tabular}{|c|c|c|c|}
\hline \multicolumn{2}{|c|}{ Carreira de 2006} & \multicolumn{2}{|c|}{ Carreira de 2008 - EBTT } \\
\hline Classe & Nível & Nível & Classe \\
\hline & & 3 & \multirow{3}{*}{ DV } \\
\hline & & 2 & \\
\hline & & 1 & \\
\hline $\mathrm{S}$ & 1 & $S$ & DIV \\
\hline \multirow{4}{*}{$\mathrm{E}$} & 4 & 4 & \multirow{4}{*}{ DIII } \\
\hline & 3 & 3 & \\
\hline & 2 & 2 & \\
\hline & 1 & 1 & \\
\hline \multirow{4}{*}{$\mathrm{D}$} & 4 & 4 & \multirow{4}{*}{ DII } \\
\hline & 3 & 3 & \\
\hline & 2 & 2 & \\
\hline & 1 & 1 & \\
\hline \multirow{4}{*}{$\mathrm{C}$} & 4 & 4 & \multirow{12}{*}{ DI } \\
\hline & 3 & 3 & \\
\hline & 2 & 2 & \\
\hline & 1 & \multirow{9}{*}{1} & \\
\hline \multirow{4}{*}{ B } & 4 & & \\
\hline & 3 & & \\
\hline & 2 & & \\
\hline & 1 & & \\
\hline \multirow{4}{*}{ A } & 4 & & \\
\hline & 3 & & \\
\hline & 2 & & \\
\hline & 1 & & \\
\hline
\end{tabular}

Fonte: Lei n. 11784, de 22 de setembro de 2008

Observa-se no quadro 2 a extinção das classes A e B, da Carreira do Magistério de $1^{\circ}$ e $2^{\circ}$ graus, de 2006 , a qual permitia o ingresso de professores sem formação no nível superior para atuarem como professores dos cursos técnicos. Além disso, observa- 
se, nesse mesmo quadro, a criação de mais uma classe, a DV, para contemplar, especificamente, os professores no final de carreira, que já estavam no plano anterior, na classe $\mathrm{S}$, há alguns anos sem qualquer possibilidade de progressão. Assim, a carreira do EBTT possibilitou uma maior mobilidade interna, termo adotado por Barbosa (1996), e estabelece a graduação como pré-requisito para o ingresso na RFEPCT.

Essa alteração prevaleceu por um curto período de tempo, pois em 2012, foi aprovada a Lei n. 12.772, que reestruturou os planos de carreira do magistério federal. A alteração mais substancial da Lei do Magistério Federal é a instituição do Reconhecimento dos Saberes e Competências, que será explicitado em seguida.

\section{A LEI DO MAGISTÉRIO FEDERAL}

Apesar de a cultura de qualificação estar presente no campo educacional, essa lei instituiu um novo "olhar avaliativo" sobre a prática pedagógica, reconhecendo os saberes experenciais/tácitos dos professores, no âmbito da Educação Profissional. Tendo em vista que o modelo atual do RSC busca de cada um, o esforço pessoal e não coletivo, a educação assume uma perspectiva individualista, posicionamento recorrente de uma sociedade capitalista, na qual, tudo parece estar voltado para os interesses do indivíduo.

O RSC inaugura uma hierarquia que divide as classes dos saberes, mais claramente, procedendo-se a uma minuciosa análise do "curriculum vitae" dos docentes, proporcionando-lhes uma "progressão" na carreira, auferindo-lhes um aumento salarial. O objetivo desta investigação é o de realizar uma imersão na realidade dos postulantes ao RSC sobre questões referentes à implantação da Lei, em pauta, que passou a vigorar a partir do dia $1^{\circ}$ de março de 2013. Segundo a Resolução CPRSC/SETEC/MEC n. 1, de 20 de fevereiro de 2014, o Reconhecimento de Saberes e Competências significa "o processo de seleção pelo qual são reconhecidos os conhecimentos e habilidades desenvolvidos a partir da experiência individual e profissional, bem como no exercício das atividades realizadas no âmbito acadêmico"

Vale destacar que a Lei que instituiu o RSC para os professores do Magistério do EBTT é a mesma que dispôs sobre a carreira dos docentes das universidades. Isso cria uma condição diferenciada entre os professores do EBTT e os demais profissionais 
de nível superior da RFEPCT e os professores das universidades, pois os professores do EBTT recebem a Retribuição por Titulação (RT) sem qualificação, mas os demais só a recebem se se qualificarem.

A Lei do Magistério Federal regulamenta não apenas a questão salarial, mas também os critérios de ingresso dos professores na Carreira, a aposentadoria, o quantitativo de cargos de professor titular e critérios para o acesso a esse cargo.

Destaca-se que foram criados, na Lei n. 12772/12, 526 cargos de professor titular-livre para a Carreira dos Professores do EBTT, além de transformar os 354 cargos de Professor Titular (criados na Lei n. 11.784/2008), totalizando 880; e 1200 cargos de professor titular-livre para a Carreira do Magistério Superior, ou seja, para os professores das Universidades Federais e CEFETs.

Pela proposta, no âmbito do novo Plano de Carreiras e Cargos, a carreira do
Magistério Superior será composta de cinco classes: Professor Auxiliar,
Professor Assistente, Professor Adjunto, Professor Associado e Professor
Titular, esta última integrada pelos atuais Professores Titulares das
instituições federais de ensino superior e acessível aos docentes das demais
classes da Carreira, por meio de promoção, desde que possuam titulação de
Doutor e observados ainda outros requisitos. A Carreira do Magistério do
Ensino Básico, Técnico e Tecnológico, por sua vez, é composta de cinco
classes: DI, DII, DIII, DIV e da nova Classe de Titular, esta última acessível
apenas para docentes com titulação de Doutor, observados ainda outros
requisitos profissionais. (Relatório, 2012)

A Lei n. 12772/12 foi alterada pela Lei n. 12683/2013, devido à reivindicação dos sindicatos dos professores das Universidades Federais, que, dentre outras questões, solicitaram a alteração do pré-requisito para o ingresso na carreira e a redução de tempo mínimo para o concurso de professor titular-livre. Ambas as reivindicações foram atendidas, pois o tempo para concorrer ao cargo de titular-livre passou de 20 para 10 anos, e o pré-requisito para o ingresso nas universidades, que era a graduação, passou a ser o título de doutor. Outra modificação oriunda da Lei n. 12.683/2013 refere-se à progressão que só era permitida após o interstício de 24 meses para cada nível, conforme quadro 3, que instituiu a aceleração da promoção para os iniciantes com formação de mestrado e ou doutorado. Assim, o professor na classe I, nível 1 (DI), com titulação em nível de pós-graduação strictu sensu, poderá ser enquadrado na classe III, nível 1 (DIII), após ser aprovado no estágio probatório. 
Apesar de a Lei em apreço ter sido aprovada em dezembro de 2012, passando a vigorar a partir de $1^{\circ}$ de março de 2013 , a regulamentação do dispositivo do RSC, só foi finalizada em 2014.

Conforme o parágrafo $3^{\circ}$, do Artigo 18, deveria ser "criado o Conselho Permanente para Reconhecimento de Saberes e Competências no âmbito do Ministério da Educação, com a finalidade de estabelecer os procedimentos para a concessão do RSC”.

Com essa finalidade foi publicada a Portaria n. 1.094, de 7 de novembro de 2013, que aprovou o Regulamento do Conselho Permanente para Reconhecimento de Saberes e Competências (CPRSC) do Plano de Carreira e Cargos do Magistério do Ensino Básico, Técnico e Tecnológico, cuja competência foi definida no seu Art. $4^{\circ}$.

\footnotetext{
I - estabelecer as diretrizes e procedimentos para a concessão do Reconhecimento de Saberes e Competências aos docentes da Carreira do Magistério do Ensino Básico, Técnico e Tecnológico;

II - analisar e homologar os regulamentos específicos de cada Instituição Federal de Ensino para o RSC;

III - orientar a supervisão do Ministério da Educação e do Ministério da Defesa sobre a concessão do Reconhecimento de Saberes e Competências pelas instituições federais de ensino;

IV - constituir e disponibilizar o banco de avaliadores, para a composição da comissão especial, de acordo com o previsto no art. $4^{\circ}$ da Portaria MEC $n^{\circ}$ 491, de 2013;

V - regulamentar o processo de habilitação dos avaliadores;

VI - estabelecer os critérios e procedimentos a serem considerados no processo de Reconhecimento de Saberes e Competências;

VII - julgar recursos interpostos relativos ao Regimento Interno para concessão do Reconhecimento de Saberes e Competências das IFEs; e VIII - julgar recursos interpostos pelos avaliados. (BRASIL, 2013)
}

O que se verificou foi que o processo de implementação foi desenvolvido pelos componentes desse Conselho, quais sejam, professores que compunham a Comissão Permanente de Pessoal Docente (CPPD), representantes dos sindicatos e do MEC. Estabeleceu-se que os professores seriam avaliados por seus pares: dois professores da instituição na qual estava vinculado o servidor que pleiteasse a concessão do RSC e dois professores de outras instituições, vinculados à RFEPCT, cujos sorteios seriam realizados por um sistema eletrônico, gerenciado pelo MEC. A par disso, os professores dariam entrada ao processo para pleitearem o RSC, e, consequentemente, receberem o aumento salarial, por meio da Retribuição por Titulação. 
Ressalta-se que a remuneração do Plano de Carreiras e Cargos de Magistério Federal estrutura-se da seguinte forma, conforme o art. 16, da Lei n. 12.772/12:

I - Vencimento Básico, conforme valores e vigências estabelecidos no Anexo III, para cada Carreira, cargo, classe e nível; e

II - Retribuição por Titulação - RT, conforme disposto no art. 17.

Ainda, conforme a referida Lei, a RT para os professores do EBTT poderá ser calculada de acordo com a concessão do RSC ao professor dessa Carreira ${ }^{2}$.

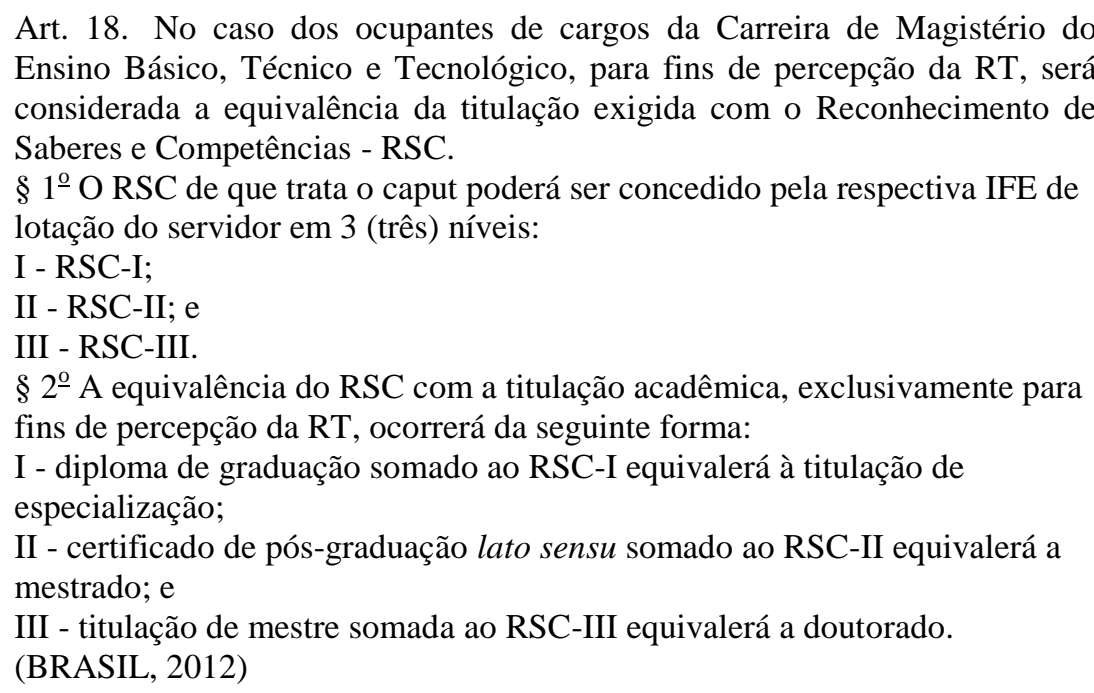

Para finalizar, segue o quadro, referente à Carreira de Magistério do Ensino Básico, Técnico e Tecnológico, retirado do Anexo I, da Lei em pauta, o qual informa as alterações efetuadas na carreira de Magistério do EBTT.

\footnotetext{
${ }^{2}$ Para conhecer a remuneração dos professores do EBTT, consulte as tabelas VII, VIII, IX e X, do Anexo IV da Lei n. 12.772/12. Como o Anexo IV é muito extenso, optou-se por colocar o link para o acesso, http://www2.camara.leg.br/legin/fed/lei/2012/lei-12772-28-dezembro-2012-774886-normaatualizadapl.pdf
} 


\section{Quadro 3: Alterações na Carreira do Magistério do Ensino Básico, Técnico e Tecnológico (EBTT)}

\begin{tabular}{|c|c|c|c|c|c|}
\hline \multicolumn{3}{|c|}{ SITUACÃO ATUAL } & \multicolumn{3}{|c|}{ SITUAÇÃO NOVA } \\
\hline \multirow{2}{*}{$\begin{array}{c}\text { CARREIRA EBTT } \\
2008\end{array}$} & CLASSE & NÍVEL & NÍVEL & CLASSE & \multirow{2}{*}{$\begin{array}{c}\text { CARREIRA EBTT } \\
2012\end{array}$} \\
\hline & & & 1 & Titular & \\
\hline \multirow{16}{*}{$\begin{array}{c}\text { Carreira de } \\
\text { Magistério do } \\
\text { Ensino Básico, } \\
\text { Técnico e } \\
\text { Tecnológico, } \\
\text { de que trata a } \\
\text { Lei n. } 11.784, \\
\text { de } 22 \text { de } \\
\text { setembro de } \\
2008\end{array}$} & \multirow[t]{3}{*}{ D V } & 3 & 4 & \multirow{4}{*}{ D IV } & \multirow{16}{*}{$\begin{array}{c}\text { Carreira de } \\
\text { Magistério do } \\
\text { Ensino Básico, } \\
\text { Técnico e } \\
\text { Tecnológico, } \\
\text { do Plano de } \\
\text { Carreiras e } \\
\text { Cargos de } \\
\text { Magistério } \\
\text { Federal, da Lei n. } \\
\text { 12.772/2012 }\end{array}$} \\
\hline & & 2 & 3 & & \\
\hline & & 1 & 2 & & \\
\hline & D IV & $S$ & 1 & & \\
\hline & \multirow{4}{*}{ D III } & 4 & 4 & \multirow{4}{*}{ D III } & \\
\hline & & 3 & 3 & & \\
\hline & & 2 & 2 & & \\
\hline & & 1 & 1 & & \\
\hline & & 4 & 2 & & \\
\hline & D II & 3 & & D II & \\
\hline & & 2 & 1 & & \\
\hline & & 1 & & & \\
\hline & & 4 & 2 & & \\
\hline & D I & 3 & & D I & \\
\hline & & 2 & 1 & & \\
\hline & & 1 & & & \\
\hline
\end{tabular}

Fonte: Lei n. 12. 772/2012, com pequenos acréscimos

Observa-se, nesse quadro, que foi criada uma classe para a Carreira do Magistério EBTT, a classe de Professor Titular e que foram retirados dois níveis nas Classes DI e DII, que anteriormente, eram quatro, mas, que na Lei, em vigor, passaram a ser apenas dois. Além disso, a Classe DIV S, conhecida como Classe Especial, incorporou-se à Classe DIV, como o primeiro nível (Nível 1).

A Classe de Professor Titular, com apenas um nível, apresenta duas situações. A primeira refere-se aos professores que já estão no serviço público e a segunda refere-se aos novos professores concursados.

No primeiro caso, os professores da RFEPCT poderão ter o acesso à Classe de Professor Titular, conforme o art. $8^{\circ}$ da Portaria MEC n. 982/2013:

$\mathrm{O}$ acesso à classe de Titular da Carreira de Magistério do Ensino Básico, Técnico e Tecnológico, dar-se-á observando os critérios e requisitos instituídos conforme inciso IV do $\S 3^{\circ}$ do artigo 14 da Lei n. 12.772, de 2012: I - possuir o título de doutor; 
II - ser aprovado em processo de avaliação de desempenho; e

III - lograr aprovação de memorial que deverá considerar as atividades de ensino, pesquisa, extensão, gestão acadêmica e produção profissional relevante, ou de defesa de tese acadêmica inédita.

Parágrafo único - A promoção ocorrerá observado o interstício mínimo de 24 (vinte e quatro) meses no último nível da classe D IV. (PORTARIA n. 982, 2013)

No segundo caso, os professores do Cargo Isolado de Professor Titular-Livre poderão ingressar no serviço público mediante concurso público de provas e títulos, caso atendam aos seguintes quesitos:

- $\quad$ título de doutor

- 10 (dez) anos de experiência ou de obtenção do título de doutor, ambos na área de conhecimento exigida no concurso, conforme orientações do Conselho Superior de cada Instituto Federal.

Conforme, atesta o art. $2^{\circ}$ da Lei n. 12.772/2012, os cargos isolados têm o objetivo contribuir para o desenvolvimento, fortalecimento das competências e alcance da excelência no ensino e na pesquisa nas instituições.

Apesar de as instituições possuírem a prerrogativa de abrirem concurso para esse cargo isolado, existe uma limitação imposta pela Portaria MEC n. 11/2016, que regulamenta o Quadro de Professor Equivalente dos Institutos Federais, cujo maior objetivo é normatizar a contração de novos docentes. Mesmo que uma instituição tenha interesse em compor seu quadro com um professor titular-livre, há o empecilho quanto ao valor desse professor, pois, de acordo com a Portaria citada, um professor titularlivre equivale a 3,32, enquanto um professor de 40h com dedicação exclusiva (DE) equivalente a 1,59. Assim, um professor titular-livre corresponde, no Quadro de Professor Equivalente ${ }^{3}$, a, aproximadamente, dois professores de $40 \mathrm{~h}$ DE. Isso acaba por incidir no número de professores da instituição. No entanto, o professor da RFEPCT que obtiver o acesso à classe titular continua equivalendo 1,59 , pois não é considerado um novo cargo.

\subsection{Reconhecimento de Saberes e Competências: simulação das condições salariais}

\footnotetext{
${ }^{3}$ Os valores referentes aos professores conforme sua jornada de trabalho é: 3,32 (professor titulat-livre), 1,59 (professor 40h - dedicação exclusiva), 1,0 (professor 40h), e 0,58 (professor 20h)
} 
A Lei n. 12772, de 28 de dezembro de 2012, que dispõe sobre a estruturação do Plano de Carreiras e Cargos de Magistério Federal, inclui os professores das Universidades Federais, pela Carreira de Magistério Superior e os professores da RFEPCT, pela Carreira do Magistério do Ensino Básico, Técnico e Tecnológico (EBTT).

Reitera-se que a seção II, desta legislação, que trata, especificamente, da carreira do EBTT, informa que, para fins de recebimento de efeito financeiro, há três níveis: RSC-I, RSC-II e RSC-III. Trata-se de uma equivalência salarial com o título imediatamente posterior. Dessa forma, o professor com título de Graduação poderá requerer o RSC-I, que equivale à titulação de Especialização; o professor com Especialização poderá requerer o RSC-II, equivalente ao Mestrado; e o professor com o título de Mestre poderá requerer o RSC-III, equivalente ao Doutorado. Destaca-se que a remuneração básica dos professores é composta pelo valor do Vencimento Básico (VB), referente à classe/nível em que se enquadra o servidor adicionado o valor da RT, correspondente à sua titulação.

Para se ter uma compreensão da composição do salário dos professores após a promulgação da lei, observe o gráfico ${ }^{4} 1$ abaixo:

\section{Gráfico 1: Evolução salarial do professor iniciante na carreira do EBTT}

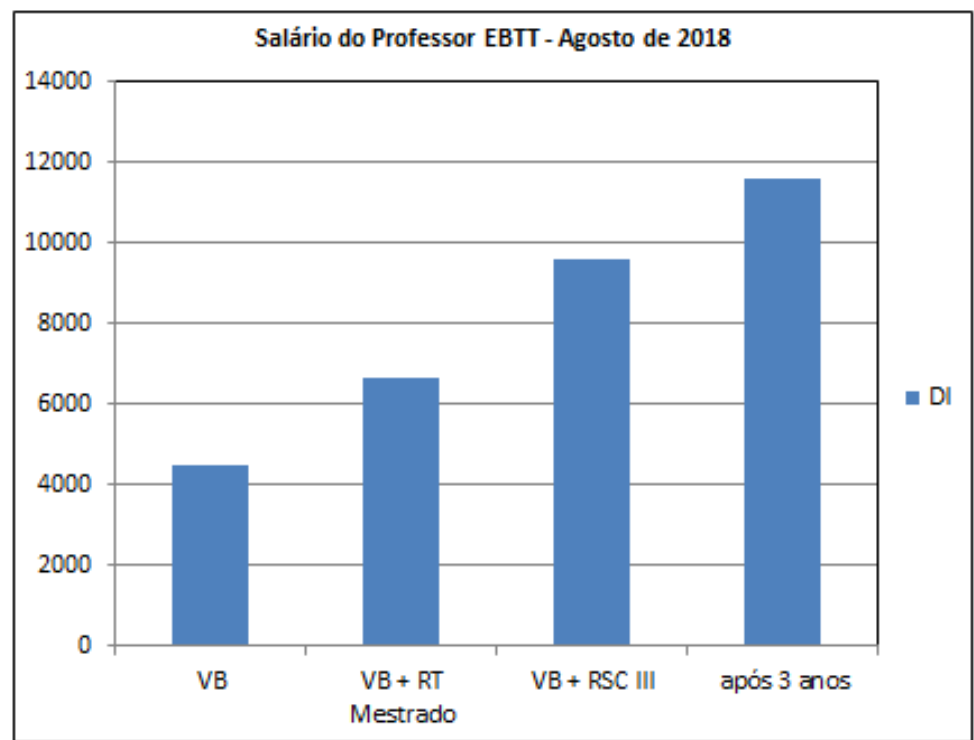

Fonte: elaborado pela autora

\footnotetext{
${ }^{4}$ Os salários foram arredondados, retirando-se os centavos.
} 
Como se pode averiguar, se o professor iniciante tiver o mestrado, receberá, aproximadamente, $49 \%$ a mais de seu salário, o equivalente à RT no nível de mestrado. E, se pleitear o RSC III, receberá, aproximadamente, $115 \%$ a mais, podendo chegar ao dobro de um professor que não tem essa certificação. Após 3 anos, caso seja aprovado no estágio probatório, quase triplicará o seu salário, passando de $\mathrm{R} \$ 4.463,93$ para $\mathrm{R} \$ 11.561,91$. O impacto financeiro com o dispositivo do RSC é bastante significativo no salário do docente. Esclarece-se que esses dados representam apenas uma simulação da condição salarial do docente da EBTT, pois há inúmeros outros casos situações que poderão compor o salário do professor iniciante, como o fato de ele ter uma especialização, não mestrado. De qualquer modo, optou-se por simular a situação de um professor com mestrado, pois, nos últimos anos a maioria dos docentes aprovados nos concursos são mestres, quando não doutores. Além disso, com a possibilidade de se afastar para a capacitação, logo após o ingresso na RFEPCT, mesmo estando em estágio probatório, o docente iniciante poderá, em menos de três anos, triplicar o seu salário, como foi apresentado no gráfico 1 .

É necessário ressaltar que o período de estágio probatório refere-se ao tempo de avaliação periódica do servidor, quando será submetido à avalição por critérios definidos pela instituição, tais como assiduidade, compromisso, capacidade de iniciativa, responsabilidade, dentre outros. A Constituição Federal de 1988 determina, no art. 41, que são estáveis, após três anos de efetivo ${ }^{5}$ exercício, os servidores nomeados para cargo de provimento efetivo em virtude de concurso público. Por outro lado, a Lei n. 8112/1990 prescreve, no art. 20, que "servidor nomeado para cargo de provimento efetivo ficará sujeito a estágio probatório por período de 24 (vinte e quatro) meses".

Quando se compara o salário de um professor iniciante com um professor aposentado antes do dia $1^{\circ}$ de março de 2013, quando a Lei n. 12.772/2012, passou a vigorar, percebem-se os impactos nas condições salariais do professor da EBTT. Segue o gráfico 2 que apresenta essa simulação.

\footnotetext{
${ }^{5}$ Observa-se que, caso o professor se afaste para a capacitação, a avaliação, referente ao estágio probatório, ficará suspensa até ele retorne ao trabalho, para que, posteriormente, ele possa, de fato, ser efetivado no cargo público.
} 


\section{Gráfico 2: Comparação entre o salário de um professor iniciante e o de um professor aposentado antes de $1^{\circ}$ de março de 2013}

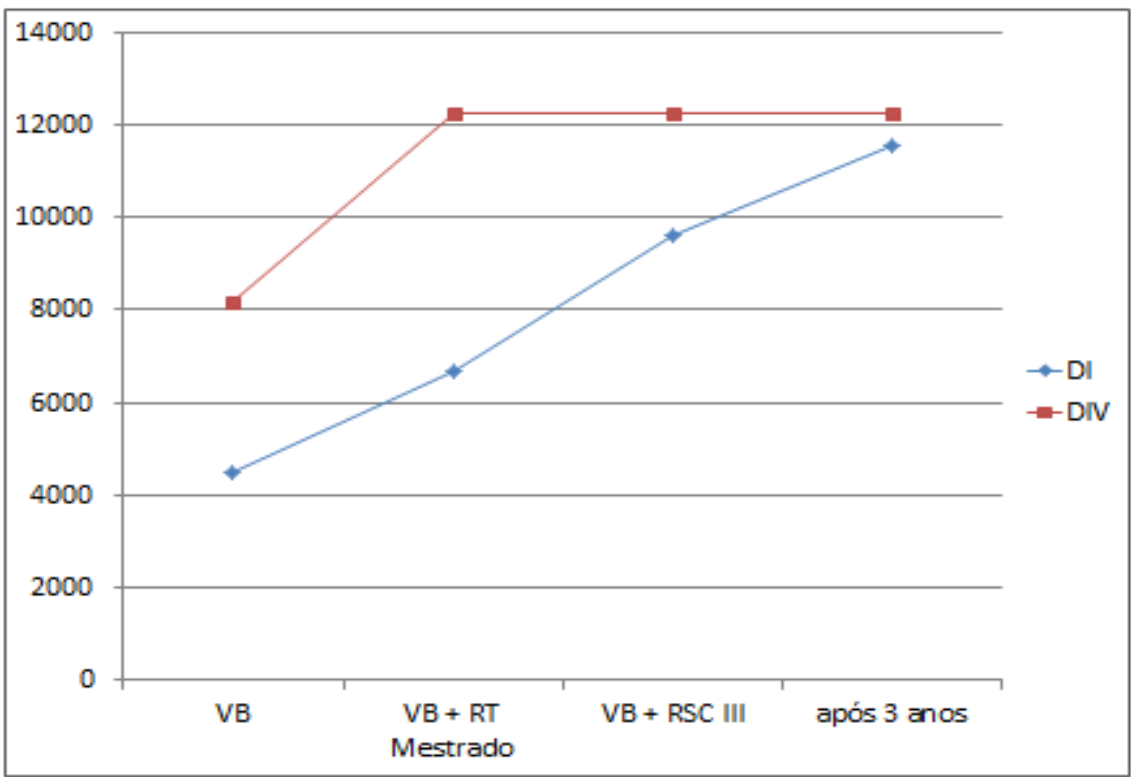

Fonte: Elaborado pela autora com base na Tabela de Remuneração dos Servidores Públicos Federais ${ }^{6}$, referente a agosto de 2018, publicada em janeiro de 2019.

No gráfico 2, a situação simulada refere-se ao salário recebido por um professor iniciante e um professor aposentado, situados na classe DI, nível 1, e DIV, nível 4, respectivamente. Neste caso, optou-se comparar professores com a mesma titulação, ou seja, ambos com mestrado, no início e no final da carreira do EBTT. Tal opção justificase pelo mesmo fato apresentado na simulação anterior. Percebe-se que o VB básico de cada um dos professores é bem diferente, o do professor aposentado equivale, aproximadamente, ao dobro do professor iniciante, $\mathrm{R} \$ 12.278 .40$ e $\mathrm{R} \$ 6.668,20$, respectivamente. Caso o professor iniciante, situado na classe $\mathrm{D}$, nível 1 , requeira o RSC III, por ter o mestrado, ele passará a receber o valor de $\mathrm{R} \$ 9.600,92$, enquanto o aposentado continuará a receber o mesmo valor. Após 3 anos, aquele professor receberá $\mathrm{R} \$ 11.561,91$, e este, com a mesma formação, receberá os mesmos $\mathrm{R} \$ 12.278 .40$, ou seja, $\mathrm{R} \$ 716,49$ a mais que o professor iniciante. Uma diferença salarial que era de, aproximadamente, $54 \%$ poderá cair, em três anos, para, aproximadamente, $6 \%$.

Destaca-se que essas simulações foram apresentadas para que se pudesse ter uma visão mais micro da Lei em apreço, e os pontos apresentados - início da carreira e professores aposentados são questões polêmicas referente ao RSC, inclusive, presentes

\footnotetext{
${ }^{6}$ Mais informações poderão ser encontradas no site http://www.planejamento.gov.br/assuntos/gestaopublica/arquivos-e-publicacoes/tabela-de-remuneracao-78-jan2019.pdf
} 
na discussão da aprovação da lei pelos deputados federais. A seção seguinte tratará da tramitação da Lei no Congresso Nacional.

\subsection{Tramitação do Projeto Lei n. 4368/2012 na Câmara dos Deputados}

O Projeto de Lei n. 4368/2012 foi construído juntamente com representantes dos sindicatos Federação de Sindicatos de Professores e Professoras de Instituições Federais de Ensino Superior e de Ensino Básico, Técnico e Tecnológico (PROIFES), Sindicato Nacional dos Servidores Federais da Educação Básica, Profissional e Tecnológica (SINASEFE) e Federação de Sindicatos de Trabalhadores Técnicoadministrativos em Instituições de Ensino Superior Públicas do Brasil (FASUBRA). A entrada desse Projeto na Câmara dos Deputados ocorreu no dia 31/08/2012 e foi executada pelo Poder Executivo, Casa Civil, assinado por Miriam Belchior.

No dia 03 de setembro de 2012, decidiu-se que quatro comissões de trabalho deveriam analisar o projeto, quais sejam:

- Trabalho, de Administração e Serviço Público;

- Educação e Cultura;

- Finanças e Tributação; e

- Constituição, Justiça e Cidadania.

No dia 11/09/2012, essas comissões receberam o Projeto e, no dia 12/09/2012, designaram o Deputado Alex Canziani (PTB-PR) como relator dos estudos.

A partir do 13/09/2012, decidiu-se que as comissões teriam um prazo de 5 sessões ordinárias para apresentarem emendas ao Projeto de Lei, em pauta, que se encerrou no dia 16/10/2012.

No dia 25/10/2012, o Projeto foi encaminhado para a Mesa Diretora da Câmara dos Deputados.

Em 21/11/2012, houve uma audiência pública para apresentação e discussão do Projeto.

No dia 28/11/2012, o Deputado Alex Canziani apresentou o Parecer com posição favorável a sua aprovação, rejeitando algumas emendas e acatando outras. Foram apresentadas 76 emendas e três deputados (Laércio Oliveira, Jean Wyllys e 
André Figueiredo), por meio das emendas 27, 63 e 18, sugeriram a supressão dos artigos 18 e 19, referentes ao RSC, apresentando a seguinte justificativa ${ }^{7}$ :

A introdução no cenário jurídico e acadêmico de equivalência à titulação exigida para recebimento da Retribuição por Titulação por meio do reconhecimento de "saberes e competências" é ambígua, desfocada da realidade vivenciada pelas instituições federais, autoritária na sua concepção e abrirá caminho para contencioso judicial. (EMC n. 27, n. 63 e n.18)

O Deputado Laércio Oliveira e André Figueiredo sugeriram a supressão dos dispositivos referentes aos cargos de professor titular-livre, com a seguinte justificação:

\begin{abstract}
A supressão dos dispositivos acima citados se dá pelo fado de que a proposta de criação de cargo isolado secciona o quadro docente e a carreira. Além disso, cria uma ambiguidade insanável entre duas figuras de professores titulares com características e formas de ingresso distintas, dramaticamente é agravada ao propor a transformação dos cargos atuais de professor titular em direções distintas.

Isto é, ao mesmo tempo em que no artigo $3^{\circ}$ determina que todos os cargos de titular preexistentes passam a pertencer ao Plano, explicitando no parágrafo $5^{\circ}$ que, no caso do MS, passam a integrar a carreira. Ademais, no artigo 38, os cargos de titular EBTT são transformados no novel titular livre. Caso viceje tal ambiguidade certamente abrirá espaço para complexo contencioso jurídico. (EMC n. 8 e n. 60)
\end{abstract}

Apesar das Emendas apresentadas por esses deputados, o relator Alex Canziani as rejeitou e a Lei foi aprovada.

Após dois anos de sua implementação a Controladoria Geral da União (CGU) fez uma auditoria em alguns processos já aprovados no IFMG e em outros institutos. O Relatório n. 201505065 detectou que dos 694 professores da instituição, 62\% recebem o RSC, o que equivalente a, aproximadamente, 430 professores. Desses 430 processos aprovados, a CGU analisou apenas três, como amostragem e detectou algumas irregularidades, entre elas:

- A utilização de um curso de pós-graduação (mestrado) como curso adicional, o que se tornou irregular porque ele era usado como pré-requisito ao RSC III.

\footnotetext{
${ }^{7}$ As justificativas dos deputados foram expressas por textos idênticos.
} 
- A informação de uma atividade de pesquisa na diretriz inadequada, pois, segundo o relatório, essa atividade comprovada se enquadraria na diretriz referente a atividades culturais.

- O parecer de um avaliador estava com incorreções, que aceitou atividades desenvolvidas em âmbito nacional, apesar de o certificado não comprovar que o evento fosse nacional.

Dos três casos analisados, dois tiveram que ser revistos pelo pleiteante ao RSC. Apenas no primeiro caso, em que o curso de mestrado foi considerado por um dos avaliadores adicional, não houve problemas, porque o pleiteante alcançaria os 25 pontos, mínimo necessário à concessão do RSC. Além disso, esse processo tinha sido aprovado por dois avaliadores, que é uma exigência para a concessão.

\subsection{Avaliação do RSC}

A regulamentação da operacionalização dos processos de RSC foi formulada pelo CPRSC, que determinou algumas diretrizes que foram seguidas pelo IFMG, sem muitas alterações. Cada instituição poderia formular seus critérios, contanto que não se desvirtuasse dessas diretrizes. Ao analisar uma planilha de outra instituição, com o objetivo de fazer uma comparação nos parâmetros de avaliação adotados por cada uma, chamou a atenção o fato de essa instituição avaliar a experiência docente de forma diferenciada conforme os níveis e modalidade de ensino. É estranho considerar, por exemplo, que trabalho desenvolvido na Educação de Jovens e Adultos tenha uma valoração menor. De maneira geral, os critérios não foram muito diferentes dos critérios adotados pelo IFMG, pois seguiram as orientações da Resolução CPRSC/SETEC/MEC n. $1 / 2014$, expressas no artigo 2.

$\S 1^{\circ}$ - Para fins de Reconhecimento de Saberes e Competências devem ser observados os seguintes perfis:

a) RSC I - Reconhecimento das experiências individuais e profissionais, relativas às atividades de docência e/ou orientação, e/ou produção de ambientes de aprendizagem, e/ou gestão, e/ou formação complementar e deverão pontuar, preferencialmente, nas diretrizes relacionadas no inciso I, do art. 11, desta resolução.

b) RSC II - Reconhecimento da participação em programas e projetos institucionais, participação em projetos de pesquisa, extensão e/ou pertinente 
inovação e deverão pontuar, preferencialmente, nas diretrizes relacionadas no inciso II, do art. 11, desta resolução.

c) RSC III - Reconhecimento de destacada referência do professor, em programas e projetos institucionais e/ou de pesquisa, extensão e/ou inovação, na área de atuação e deverão pontuar, preferencialmente, nas diretrizes relacionadas no inciso III, do art. 11, desta resolução. (CPRSC/SETEC/MEC, 2014) (grifo nosso)

Conforme se observa na planilha do IFMG, as diretrizes foram definidas em três blocos, que correspondem aos níveis do RSC I, II e III. De acordo com a citação acima, os perfis para cada nível vão se apresentando mais exigentes, partindo de "experiências individuais" até se chegar a uma "destacada referência" profissional.

As diretrizes 1 são destinadas aos professores que pleiteassem o RSC I, nas quais as experiências anteriores ao exercício na instituição foram computadas e a pontuação máxima de 100 pontos. O postulante ao RSC I devem alcançar pelo menos $50 \%$ desses pontos. Já os postulantes ao RSC II e ao RSC III, devem pontuar com o mínimo de $25 \%$, nessa primeira diretriz, mas tem que alcançar $50 \%$ da pontuação no nível pretendido - RSC II ou RSC III.

As diretrizes 2, relacionam mais à formação, produção de conhecimento tecnológico além de participação em bancas de concurso e ocupação de cargos de direção. Essas diretrizes tinham uma pontuação maior nos quesitos referentes à produção de tecnologia. O valor destinado a essa produção é de 10 pontos, no entanto, as atividades escolares têm o valor menor, pois eram avaliadas por período de tempo de exercício, não por produção, mas continuarão sendo consideradas para os demais níveis.

A diretriz 3, refere-se mais à produção acadêmica, tais como publicação de artigos e/ou livros, para as quais foi destinada uma pontuação maior.

Como se observou, a produção de maior valor são as destinadas aos protótipos tecnológicos e à formação acadêmica, incluindo, cursos adicionais em nível de graduação e pós-graduação. Os professores entrevistados teceram algumas críticas em relação à planilha adotada pelo IFMG quanto a:

- Qualidade de produção de material didático;

- Importância de cursos de $180 \mathrm{~h}$ para a execução do trabalho como docente;

- Dificuldade de se alcançar os pontos referentes ao RSC II; 
- Dificuldade de se comprovar trabalhos desenvolvidos há anos na instituição sem que tivesse uma portaria ou outro documento para comprová-lo.

- Dificuldade de compreensão do processo de avaliação do RSC pelos professores com mais tempo na instituição.

Diante dessas ressalvas apontadas pelos professores entrevistados, percebe-se que os professores novatos tiveram menos dificuldade de serem aprovados nos processos que os docentes mais experientes. Um dos motivos que pode explicar isso concerne no fato de que esses professores desenvolveram seu trabalho, exclusivamente, em sala de aula e/ou laboratórios. No entanto, esse trabalho apresenta dificuldade de ser avaliado no momento em que ele se desenvolve, e mais complicado ainda, quando se trata de um trabalho desenvolvido no passado, numa época em que a organização do trabalho era bastante diferente do que é hoje.

Enfim, os saberes experienciais foram valorados pela planilha, mas os professores tiveram dificuldade para comprová-los. Os saberes científico-tecnológicos foram privilegiados pela planilha com um valor maior, no entanto, não se pode deixar de considerar que o trabalho em sala de aula é constante, e foi avaliado em termos de tempo, enquanto a produção tecnológica foi avaliada no aspecto quantitativo. O mesmo vale para os cursos de 180h, de graduação e pós-graduação.

\section{À GUISA DE CONCLUSÃO}

É importante destacar que esta pesquisa parte do pressuposto de que a carreira docente é um dos importantes requisitos para se constituir a valorização do trabalho docente. Os interesses por uma sociedade mais justa e igualitária passa pelo reconhecimento da importância do trabalho docente. No entanto, a escola e, em especial, os professores têm sido alvo de discursos que denigrem a sua imagem em detrimento da eficácia e eficiência produtiva. No final do século XX, com o discurso da universalização escolar a toda população brasileira - destaca-se que, em 1997, a necessidade de se lutar pela igualdade tornou-se premente. A universalização do ensino fundamental, com uma série de exigências, tornou-se robusta para menos, uma vez que as políticas desenvolvidas nessa direção foram fragmentadas. No entanto, neste 
momento histórico, o Brasil passa por reformas neoliberais que se distanciam desse objetivo. Os discursos circulantes que culpabilizam os professores e a escola pela desigualdade social distorcem os objetivos da luta por uma sociedade mais igualitária.

As políticas públicas de valorização do trabalho docente, muitas vezes são desconhecidas pelos docentes, sobretudo, os dispositivos normativos que regem as suas próprias carreiras, ficando sem questionar as determinações emanadas pelo poder executivo.

É evidente que a carreira do professor da Educacional Profissional é bastante atrativa em comparação com a carreira do magistério do Estado de Minas Gerais e de muitos outros municípios. A discrepância salarial, as condições de trabalho, o incentivo à capacitação, são elementos que distinguem essas carreiras e confirmam a deficiência do sistema federalismo de cooperação. Do mesmo modo como há discrepância salarial entre a carreira docente e as demais carreiras do serviço público de mesmo nível de escolaridade. Observa-se, portanto, que o Reconhecimento de Saberes e Competências, instituído pela Lei 12,772/2012, tornou-se uma política pública direcionada à valorização do docente isolada dos demais sistemas de ensino.

É preciso, pois, compreender que

Esse é tempo de partido, tempo de homens partidos.

As leis não bastam. Os lírios não nascem da lei. Meu nome é tumulto, e escreve-se na pedra.

O poeta

declina de toda responsabilidade na marcha do mundo capitalista e com suas palavras, intuições, símbolos e outras armas promete ajudar a destruí-lo

como uma pedreira, uma floresta um verme.

(Carlos Drummond de Andrade)

\section{REFERÊNCIAS}

BRASIL. Lei ${ }^{\circ}$. 11.784, de 22 de setembro de 2008. Dispõe sobre a reestruturação do Plano Geral de Cargos do Poder Executivo - PGPE, de que trata a Lei ${ }^{\circ}{ }^{11.357}$, de 19 de outubro de 2006, do Plano Especial de Cargos da Cultura, de que trata a Lei no 
11.233, de 22 de dezembro de 2005, do Plano de Carreira dos Cargos TécnicoAdministrativos em Educação, de que trata a Lei no 11.091, de 12 de janeiro de 2005 (...) e dá outras providências. Disponível em <http://www.planalto.gov.br/ccivil_03/_Ato20072010/2008/Lei/L11784.htm>. Acesso em 20/06/2016

BRASIL. Lei $\mathrm{n}^{\circ}$. 11.892, de 29 de dezembro de 2008. Institui a Rede Federal de Educação Profissional, Científica e Tecnológica, cria os Institutos Federais de Educação, Ciência e Tecnologia, e dá outras providências. Diário Oficial da União, Brasília, DF, Seção 1. p.1 30 dez. 2008.

BRASIL, MEC. Lei n ${ }^{\circ} 12772$, de 28 de dezembro de 2012. Dispõe sobre a estruturação do Plano de Carreiras e Cargos de Magistério Federal.

DOMINIK, Érik. A carreira docente EBTT: aspectos específicos e legislação. Bambuí: Érik Campos Dominik, 2017.

FRIGOTTO, G. Educação e a crise do capitalismo real. São Paulo: Cortez, 1999.

FRIGOTTO, G. (org.). Escola "sem" partido: esfinge que ameaça a educação e a sociedade brasileira. Rio de Janeiro: UFRJ, LPP, 2017.

GADOTTI, M. Educação e poder: introdução à pedagogia do conflito. São Paulo: Cortez, 2012.

GARIGLIO, J. A.; BURNIER, S. Saberes da Docência na Educação Profissional e Tecnológica: um Estudo sobre o olhar dos professores. Educação em Revista, Belo Horizonte, v.28, n.01, p. 211-236, mar. 2012.

GATTI, B. A. Valorização da docência e avaliação do trabalho docente: o papel da avaliação participativa em um contexto institucional. In: GATTI, B. A. (Org.). O trabalho docente: avaliação, valorização, controvérsias. Campinas: Autores Associados, 2013, p. 153- 176.

HARVEY, D.. O neoliberalismo: história e implicações. 3. ed. São Paulo: Edições Loyola, 2012.

OLIVEIRA, M. A. Formação/profissionalização de professores e formação profissional e tecnológica: fundamentos e reflexões contemporâneas. Belo Horizonte: Editora PUC Minas, 2013, p. 93-121.

ROPÉ, F.; TANGUY, L. (orgs.). Saberes e Competências: O uso de tais noções na escola e na empresa. Campinas, SP: Papirus, 1997.

SANTOS, J. S. W.; CHAVES, V. L. J. Reconhecimentos de Saberes e CompetênciasRSC e as novas configurações da carreira dos Professores Federais do Ensino Básico, Técnico e Tecnológico-EBTT. In: Universidade e Sociedade - Andes - SN. N. 59, jan. 2017, p. 86-91. 
TREVISAN, A. L. Reconhecimento do outro: teorias filosóficas e formação docente. Campinas, SP: Mercado das Letras, 2014 